\title{
Pearl Formation: Persistence of the Graft During the Entire Process of Biomineralization
}

\author{
S Arnaud-Haond ${ }^{1, *}, \mathbb{\triangle}, E$ Goyard ${ }^{1}, V$ Vonau $^{1}, C$ Herbaut $^{2}, \mathrm{~J} \mathrm{Prou}^{1 \dagger}$, D Saulnier $^{1 \dagger}$
}

1Laboratoire d'Aquaculture tropicale, IFREMER/COP, BP 7004, 98719 Taravao,Tahiti, French Polynesia;

2Laboratoire de Génétique Moléculaire Humaine , Université du Pacifique, Tahi i,French Polynesia;

Present address: * CCMAR - Center for Marine Sciences, F.C.M.A.- Univ. Algarve, Gambelas, P8005-139, Faro , Portugal; †Laboratoire de Génétique et Pathologie IFREMER, BP 133, 17390 La Tremblade,France;

凹: sarnaud@ualg.pt

\begin{abstract}
:
Most bivalves species of the genus Pinctada are well known throughout the world for production of white or black pearls of high commercial value. For cultured pearl production, a mantle allograft from a donor is implanted into the gonad of a recipient oyster, together with a small inorganic bead. Because of the dedifferentiation of cells during the first steps of the host oyster's immunological reaction, so far the fate of the graft and its exact role in the process of pearl formation could not be determined via classical histological methods. Here we report the first molecular evidence of the resilience of the graft in the recipient organism by showing that cells containing genome from the donor are still present at the end of pearl formation. These results suggest the existence of a unique biological cooperation leading to the successful biomineralization process of nacreous secretion in pearl formation.
\end{abstract}

Keywords: Pearl oyster - biomineralization - grafting - pearl sac - pearl - genotype 


\section{Introduction}

During grafting, a live tissue fragment or graft prepared from the mantle of a donor pearl mollusc is implanted into the gonad of a recipient pearl mollusc altogether with a small inorganic bead, often referred to as the nucleus, in contact with the graft. Cultured black pearls from Pinctada margaratifera show a wide range of colour and lustre, which are the most important characteristics determining their commercial value. This variation is likely to be influenced by both environmental and genetic factors. The latter may depend on the recipient oyster, but professional grafters commonly consider that the colour and lustre of pearl is often related to the phenotypic properties of donor (rather than of recipient) oyster (Wada and Komaru 1996). The operation of graft induces a great upheaval in the recipient organism, including an immunological reaction and cell differentiations that make it difficult to track the different cells until the development around the bead of a follicle called "pearl-sac", and the beginning of nacreous secretion. For that reason, none of the histological studies performed during this early stage were able to determine clearly the becoming of the graft cells (Herbaut et al. 2000).

In the absence of evidence, opinions diverge as to the role and fate of the mantle allograft in the recipient. On one hand it may influence the very first steps of pearl sac formation and the secretion of the very first nacreous layers of the pearl before being rejected by the immunological response of the host. On the other hand, if it persists in the host during the whole course of pearl formation, it would imply an exceptional rate of graft success, as well as a unique biological cooperation between cells from distinct individuals with distinct genotypes in the nacreous secretion process. In an attempt to 
clarify its role and presence all along the course of biomineralization, we tried to detect its presence using molecular methods, to screen for the occurrence of a foreign genotype in the pearl sac of the recipient oyster. We compared the genomes in the muscles and pearl sacs of 80 black-lipped pearl oysters, Pinctada margaritifera, at the day of harvesting (about 18 months after the graft), using three co-dominant polymorphic molecular markers (Arnaud-Haond et al. 2002, Arnaud-Haond et al., 2003a, ArnaudHaond et al., 2003b).

\section{Material and Methods}

\section{Sampling and extraction}

Two series of 50 and 30 pearl oysters were collected 18 month after grafting, at the time of pearl collection. The pearl sac was extracted with the pearl in, and the cells layer around the pearl were carefully split until obtaining a layer of one cell width surrounding the pearl. This layer and a piece of the abductor muscle of the recipient oyster were both labelled identically and preserved in ethanol $80 \%$. The second series of 30 pearl oysters was sampled and processed after the first series of 50 had been entirely analyzed. This was done in order to make sure that the discrepancies observed between the genotypes of pairs of muscles and pearl sacs was a repeatable observation, and could not be attributed to some incident mixing of the sample during the sampling of genotyping processes.

The procedure of DNA extraction, precipitation and storage were similar to those described in Sambrook et al. (1989), using approximately 0.5g of chopped and 
subsequently air-dried tissue. The nucleic acid pellet obtained after precipitation in $100 \%$ ethanol was washed with $70 \%$ ethanol, air-dried, resuspended in 100 to $200 \mu$ l of deionized water and preserved at $-20^{\circ} \mathrm{C}$. Concentration of DNA extraction was estimated by fluorometry, and all extractions were re-diluted to get a standardize concentration of DNA of 50ng/ $\mu$ l for each extract.

\section{Polymerase Chain reaction and genotyping}

Three markers developed (Arnaud-Haond et al. 2002) using the DALP method (Direct Amplification of Length Polymorphism; (Desmarais et al. 1998), and the EPIC method (Exon Primers Intron Crossing;(Palumbi 1995) were used: pinucl2, pinucl3, and pinaldo (Table 1).

PCR was performed in a $20 \mu \mathrm{l}$ reaction volumes with final concentrations of $300 \mu \mathrm{M}$ each dNTPs, $1.8 \mathrm{mM} \mathrm{MgCl}_{2}, 0.4 \mu \mathrm{M}$ of each primer, about $100 \mathrm{ng}$ of template DNA, $1 \mathrm{X}$ Taq buffer and 0.75 units of Taq polymerase. For all PCR reaction, a negative control was used, replacing DNA by nanopure water, in order to ascertain the absence of contamination of the PCR reaction by checking this negative control would always lead to the absence of PCR product. PCR products were separated through $6 \%$ denaturing polyacrylamide gels (acrylamide:bisacrylamide, 29:1, 7M Urea) using 1X Tris-BorateEDTA buffer, running each pair of samples (the DNA extracted from pearl sac and from the corresponding adductor muscle) were run in neighbouring lanes in order to facilitate the comparison of the genotypes revealed by PCR in each tissue. The gels were then silver stained according to Bassam et al. (1991).

\section{Results and Discussion}


For the three locus pinucl 2, pinucl 3 and pinaldo, among the respectively 5, 5 and 6 alleles observed over the entire samples analyzed in Polynesia (Arnaud-Haond et al. 2002; Arnaud-Haond et al., 2003b; Arnaud-Haond et al. 2004), respectively 3, 3 and 6 were observed in the two series of grafted oysters analyzed. In the first series of 50 oysters analyzed at the time of pearl collection, they allowed revealing differences in the genotype of the muscle and pearl sac cells in respectively 43,44 and $7 \%$ of the sample pairs successfully genotyped. Due to the high sensitivity of PCR, it is very probable that an admixture of host and donor genotypes were amplified from the isolated pearl sac, but in any case the discrepancies between the genomes from muscle and pearl sac demonstrate the presence of donor cells as well as their corresponding genome in the pearl sac at the moment of pearl collection, 18 months after grafting. Indeed in some cases, three bands appeared on the lane corresponding to the pearl sac, resulting from the simultaneous amplification of distinct alleles from donor and receiver oysters that were both present in the pearl sac. Similar results were obtained on the second series of 30 oyster analyzed after. The joint analyses of both series resulted in the distinction of about 65\% pairs of distinct genotypes in pearl sacs versus muscle tissue (Table 2). In most cases where differences were highlighted, two bands were observed in the lane corresponding to the amplification product from pearl sac extract (Figure 1), one band being absent in the corresponding muscle PCR product. This implies most receiver oysters were homozygote, and donors may have been homozygotes for the distinct allele appearing in the pearl sac, or heterozygote with only one allele in common with the host oyster.

Once established the presence of donor cells in the pearl sac 18 months after grafting by the recognition of a foreign genotype present altogether with the host genotype in the 
pearl sac, we wanted to screen for the extent of this process. The next question we aimed to answer was therefore whether the grafted cells from the donor systematically persisted in the pearl sac during the entire process of pearl formation, or only occasionally. The probability of occurrence of each possible monolocus genotype was therefore estimated according to allelic frequencies at each loci, assuming Hardy Weinberg equilibrium and random mating. The expected probabilities of the donor and recipient oyster genotypes to be distinguishable were computed on the basis of those multilocus genotype probabilities. We did expect to actually observed distinct genotypes while comparing PCR products issued from pearl sac and muscle extract in all the cases where the "donor oyster" beard at least one allele that was not present in the "recipient oyster" genome. This probability allowed estimating the number of cases in which we expected to observe distinguishable genotypes for at least one loci, under the assumption the donor cells would systematically contribute to the pearl sac formation, and the genome of the donor would therefore always be present in the pearl sac. This value was compared to the observed number of cases in which distinguishable genotypes were indeed amplified from extracts of pearl sac and its corresponding adductor muscle (Table 2). A chi-2 test was then performed to test and showed that $V_{\text {obs }}$ and $V_{\exp }$ were not significantly different $(\chi 2=0.58$, with a $\mathrm{ddl}=2 ; \mathrm{p}>0.25)$, supporting the hypothesis that the pearl sac was systematically bearing cells and genome from the donor oyster.

The pearl sac, which formation is induced by the graft process, is composed of a single layer of epithelial cells, which origin remained unclear so far due to the process of cell dedifferentiation and proliferation following the grafting (Machii 1968; Herbaut et al. 2000) that did not allow to trace the fate of the graft cells using classical 
histological methods. We found a high number (about 65\%) of differences between the muscle and corresponding pearl sac genotypes (Figure 1). The proportion of indistinct muscle-pearl sac genotypes is not significantly different from the expected proportion of non distinguishable genotypes between distinct individuals of the population where the host oyster came from. These results support the systematic survival of grafted mantel cells in the recipient oyster during the whole process of pearl formation, and their participation to the constitution of the pearl sac that secretes nacreous layers. In agreement with the empirical observations of professional grafters, this study supports the idea that the part of the pearl properties determined by genetic factors can be influenced by the donor genome, thus making pearl formation a unique example of collaboration by distinct genomes in a biomineralization process. In the framework of future genetic selection programs, efforts may therefore be focused on selection not only the recipient, but also the donor oyster.

\section{Acknowledgements}

We thank Gaby, from Takapoto and the Ministery for Pearl Culture in Papeete for providing samples, and two anonymous referees for useful comments on a preliminary version of this manuscript. 


\section{References}

Arnaud-Haond S, Boudry P, Saulnier D, Seaman T, Vonau V, Bonhomme F, Goyard E (2002) New anonymous nuclear DNA markers for the pearl oyster Pinctada margaritifera and other Pinctada species. Molecular Ecology Notes 2: 220-222

Arnaud-Haond S, Bonhomme F, Blanc F (2003a) Large discrepancies in differentiation of allozymes, nuclear and mitochondrial DNA loci in recently founded Pacific populations of the pearl oyster Pinctada margaritifera. Journal of Evolutionary Biology 16(3):388-398

Arnaud-Haond S, Vonau V, Bonhomme F, Boudry P, Prou J, Seaman T, Veyret M, Goyard E (2003b) Spat collection of the pearl oyster (Pinctada margaritifera cumingii) in French Polynesia: an evaluation of the potential impact on genetic variability of wild and farmed populations after 20 years of commercial exploitation. Aquaculture 219: 181-192

Arnaud-Haond S, Vonau V, Bonhomme F, Boudry P, Prou J, Seaman T, Goyard E (2004) On the impact of cultural practices on genetic resources: evolution of the genetic composition of wild stocks of pearl oyster (Pinctada margaritifera cumingii) in French Polynesia after ten years of spat translocation. Molecular Ecology 13: 2001-2007.

Bassam BJ, Caetano-Anolles G, Greshof PM (1991) Fast and sensitive silver-staining of DNA in polyacrylamide gels. Anal of Biochemistry 196: 80-83

Desmarais E, Lannneluc I, Lagnel J (1998) Direct Amplification of Length Polymorphism (DALP), or how to get and characterise new genetic markers in many species. Nucleic Acid Research 26(6): 1458-1465 
Herbaut C, Hui B, Herbaut J, Remoissenet G, Boucaud E (2000) The pearl: isolation of outside bodies by molluscs: evolution of the graft and the pearl-sac in Pinctada margaritifera (Mollusca, Lamellibranchia). Bulletin De La Societe Zoologique De France 125: 63-73

Machii A (1968) Histological studies on the pearl sac formation. Bulletin of the Pearl Research Laboratory 13: 1489-1539

Palumbi SR (1995) Nucleic acids II: The polymerase chain reaction. In: D. Hillis and C. Moritz e (ed) Molecular systematics, Sinauer, Sunderland, Massachusetts, pp 205-247

Sambrook J, Fritsch EF, Maniatis T (1989) Molecular cloning, $2^{\text {nd }}$ edition. Cold Spring Harbor laboratory. Cold Spring Harbor, N. Y.

Wada KT, Komaru A (1996) Color and weight of pearls produced by grafting the mantle tissue from a selected population for white shell color of the Japanese pearl oyster Pinctada fucata martensii (Dunker). Aquaculture 142: 25-32 
Figure 1: Electrophoresis gel showing differences between PCR products for the locus pinucl 2 amplified from genomic DNA extracted from muscle (M) and corresponding pearl sac (PS) tissues from five oysters. From left to right, each pair of sample show a different genotype with pinucl 2 (M homozygote for the allele 250 and PS heterozygote with the alleles 210 and 250), pinucl 3(M homozygote for the allele 110 and PS heterozygote with the alleles 100 and 110), and pinaldo (M homozygote for the allele 100 and p heterozygote with the alleles 090 and 100). 
Table 1: Detail of the loci used, with the sequence of each primer, the range of size of the fragments on the basis of sequences, the list and name of alleles observed over Polynesian archipelagoes, with the alleles observed in the two series of grafted pearls analyzed indicated in bold.

\begin{tabular}{|c|c|c|c|}
\hline Locus & Primers & Range size & alleles \\
\hline \multirow[t]{2}{*}{ Pinucl2 } & TAGGGTACAGTCCGAGGTGTTCCG & $270-320$ & $(210)(220)(230)(240)(250)$ \\
\hline & TCATTAATTGTCGAAAACTTGTC & & \\
\hline \multirow[t]{2}{*}{ Pinucl3 } & CCCAAAATTGTTCGGGGAGC & $170-190$ & $(090)(\mathbf{1 0 0})(\mathbf{1 1 0})(120)(\mathbf{1 3 0})$ \\
\hline & CCCAAAATTGTTCGGGGAGC & & \\
\hline \multirow[t]{2}{*}{ Pinaldo } & CTTTGCAACGGCTGTATAGC & $80-100$ & $(070)(080)(085)(090)(095)(100)(110)$ \\
\hline & TAGGCCACCCAATCAGAGTTC & & \\
\hline
\end{tabular}


Table 2: The expected numbers of undistinguishable genotypes are estimated on the basis of allele frequencies and consequent pairs of possible multilocus genotypes. They are compared to the observed number of pairs of distinct genotypes (when comparing pearl sac and corresponding muscle) after amplification of the locus pinucl2, pinucl3 and pinaldo on a total of 80 pairs of samples analyzed. The Khi square test applied on the values from the three loci ( $\chi 2=0.58 ; \mathrm{p}>0.25)$ did not allow rejecting the hypothesis that the pearl sac would be systematically constituted of cells from the graft, bearing in some cases a genotype that could not be distinguished from the host genotype.

\begin{tabular}{l|cccc} 
& pinucl 2 & pinucl3 & pinaldo & overall \\
\hline expected & 38.86 & 33.68 & 5.71 & 17.52 \\
observed & 43 & 35 & 8 & 25 \\
\hline
\end{tabular}


Pinucl 2 Pinucl 3 Pinaldo

$M$ PS $M$ PS $M$ PS

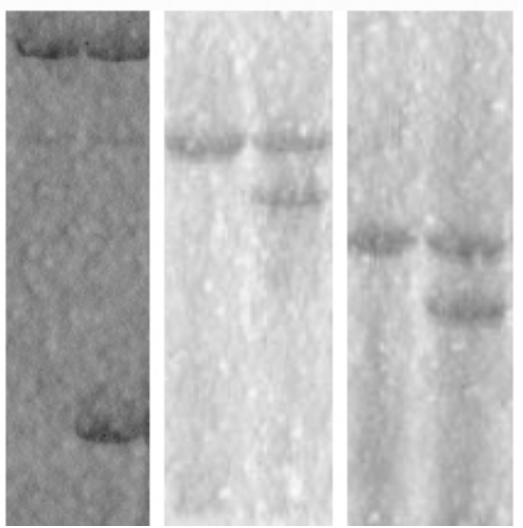

